\title{
2 Challenges in the measurement of emissions of nitrous oxide 3 and methane from livestock sector
}

\author{
4 Araceli Larios - Satinder Kaur Brar - Antonio Avalos Ramírez • \\ 5 Stéphane Godbout - Fabiola Sandoval • Joahnn H. Palacios
}

6

7 C Springer Science+Business Media Dordrecht 2016

8 Abstract Over the past two decades, the interest to 9 decrease the emission levels of greenhouse gases 10 (GHGs) has increased. The livestock sector has been 11 put under continuous supervision and regulation 17 AQ1 because it is an important source of GHG emissions. 13 @ 012 , it was estimated that $3.46 \mathrm{Gton} \mathrm{CO}_{2}$-eq was 14 released from this sector, methane $\left(\mathrm{CH}_{4}\right)$ being the gas 15 with the highest contribution (43\%), followed by 16 nitrous oxide $(21 \%)$. In order to determine real 17 emissions, it is necessary to use precise and repro18 ducible measuring methods which can be complex and 19Q2 expensive. The challenges in these methods are 20 ised on achieving an accurate assessment and

A1 A. Larios · S. K. Brar ( $\square)$ - A. A. Ramírez - F. Sandoval

A2 Institut National de la Recherche Scientifique (INRS),

A3 Centre Eau, Terre \& Environnement, 490, rue de la

A4 Couronne, Québec, QC G1K 9A9, Canada

A5 e-mail: satinder.brar@ete.inrs.ca

A6 A. A. Ramírez

A7 Centre National en Électrochimie et en Technologies

A8 Environnementales (CNETE), 2263, av. du Collège,

A9 Shawinigan, QC G9N 6V8, Canada

A10 S. Godbout $\cdot$ J. H. Palacios

A11 Institut de Recherche et de Développement en

A12 Agroenvironnement (IRDA), 2700 rue Einstein, Québec,

A13 QC GIP 3W8, Canada

A14 F. Sandoval

A15 Instituto Tecnológico Superior de Perote, Km 2.5.

A16 Carretera Perote- México, 91270 Perote, Veracruz, Mexico monitoring of gas emissions, developing monitoring systems for the continuous measurement and implementation of methodologies for their validation in field in order to understand the complex nature of environmental variables affecting gas production. Different techniques for the measurement of $\mathrm{CH}_{4}$ and nitrous oxide $\left(\mathrm{N}_{2} \mathrm{O}\right)$ emissions are reviewed and discussed in this research. The passive flux sampling to measure emissions of these GHGs has been identified as an interesting alternative technique because it is practical, low cost and robust. This kind of sampler is highly adequate to measure emissions of $\mathrm{N}_{2} \mathrm{O}$ and $\mathrm{CH}_{4}$ originating from some sources of the livestock sector, but at this moment, no prototypes are commercially available and thus more research is necessary in this field.

Keywords Greenhouse gas emissions · Measuring techniques · Livestock sector $\cdot$ Methane $\cdot$ Nitrous oxide $\cdot$ Passive flux sampler

\section{Introduction}

Livestock sector is growing at a faster pace. Total meat and milk production around the world increased from 256 to 310 million tons and from 651 to 747 million tons, respectively during 2005-2013 (FAOSTAT 2015). This faster growth has been associated with the increase of population and with the shifts in

\begin{tabular}{|l|lll|}
\hline & Journal : Medium 11157 & Dispatch : 18-3-2016 & Pages : 13 \\
Article No. : 9394 & $\square$ LE & $\square$ TYPESET \\
MS Code : RESB-D-15-00100 & $\checkmark$ CP & $\checkmark$ DISK \\
\hline
\end{tabular}


consumption patterns (Van Beek et al. 2010). Thus, livestock sector has been considered as an opportunity for economic growth and poverty reduction in rural areas (Stubbs 2010). However, livestock sector also generates environmental impacts, such as: land degradation, loss of biodiversity, spread of infectious diseases, and pollution from effluents and GHG emissions.

Livestock sector is the main source of GHG emissions from agriculture; in 2012, this sector contributed $65 \%$ of total agricultural GHGs emissions. Enteric fermentation and manure left on pasture from grazing livestock are important emission sources, representing 38.6 and $15.4 \%$ of the total agricultural emissions, respectively (FAOSTAT 2014). The manure management, and the manure applied to soils are also sources of GHGs emissions, representing 6.8 and $3.5 \%$, respectively.

The main source of $\mathrm{CH}_{4}$ emissions is the enteric fermentation and $\mathrm{CH}_{4}$ is released through ruminant eructation (Murray et al. 1999; Crutzen et al. 2006), whilst $\mathrm{N}_{2} \mathrm{O}$ is mainly produced and released during nitrification and denitrification process from $\mathrm{NH}_{3}$ present in urine and feces (Monteny et al. 2006; Solomon 2007). Non-dairy cattle contribute $41 \%$ of total GHGs emissions from livestock sector, followed by production of cattle dairy (20\%), buffaloes (9\%), sheep and goats $(6.5 \%)$. The production from other non-ruminant species, such as pigs and poultry contribute 9 and $8 \%$, respectively (Gerber et al. 2013; FAO 2014).

Livestock production systems vary significantly around the world depending on cultural, socio-economic and environmental conditions. In general, livestock production systems can be classified as; grazing, confinement and mixed system. The main differences between them are related to the housing type, feeding operations and manure management. In grazing systems, the animals are raised on extensive dry land areas, such as savannas, grasslands, scrublands and deserts or in deciduous and evergreen forests areas. These systems exist in $25 \%$ of global land area. Major countries with most land area in grazing systems comprise Australia, China, United States, Brazil and Argentina (Asner et al. 2004; Rearte and Pordomingo 2014). These systems are used to raise cattle, buffaloes, sheep and goats. In these systems, $\mathrm{CH}_{4}$ and $\mathrm{N}_{2} \mathrm{O}$ emissions are released directly to the atmosphere as animals are raised in outdoor conditions and their excreta is immediately deposited on the grassland (Asner et al. 2004).

In confined animal farming operations, the animals are fattened intensively with concentrated feed, complemented with fodder, and crops, such as soybean and corn (Hafla et al. 2013). In these systems, the temperature, air circulation and waste disposal can be controlled. There are separate buildings for noncattle and cattle production. The non-cattle buildings are mechanically ventilated, such as buildings used to raise pigs and poultry. The buildings for cattle production are naturally ventilated or with a combined system normally referred to as hybrid ventilation (Arogo et al. 2003; Godbout et al. 2012). GHGs emissions from confined system are released to the atmosphere in the air flux exiting the system. These systems are mainly distributed in the East and Southeast Asia, Europe and North America, Southern Brazil and some regions of Mexico, Colombia, Venezuela, Nigeria, and Australia.

The mixed systems are commonly used to raise ruminants around the world in intensive and extensive mode producing about $75 \%$ of milk and $60 \%$ of meat from ruminants around the world (Herrero et al. 2010). These systems are characterized by integration of livestock and arable crop production. The animals are maintained in farms near land crops, where they are fed mostly on grass and non-food biomasses obtained from maize, millet, rice, and sorghum crops, and manure is used as organic fertilizer on land crops. Arogo et al. (2003) has estimated that $64 \%$ of global $\mathrm{CH}_{4}$ emissions from enteric fermentation are issued from mixed systems, whereas grazing systems generate $34 \%$.

\section{Basic principle on the measurement of GHGs emissions}

As emissions represent mass of a gas released by a source per unit of time, the measurement of GHGs emission generally requires techniques and instruments to measure the concentration of gas (s) target; and the air exchange rate or the vertical and horizontal flux from a specific area. The measurement of gas concentration can be done by direct detection in situ using sensors or gas analyzer or by applying techniques of sampling for after to measure gas concentration in laboratory or in mobile unites installed in

\begin{tabular}{|l|lll|}
\hline & Journal : Medium 11157 & Dispatch : 18-3-2016 & Pages : 13 \\
Article No. : 9394 & $\square$ LE & $\square$ TYPESET \\
MS Code : RESB-D-15-00100 & $\checkmark$ CP & $\checkmark$ DISK \\
\hline
\end{tabular}


142 field. In next sessions a brief description of current 143 techniques to measure gas concentration and air 144 velocity is done. After the measurement of gas 145 concentration and air flux, specific equations are used 146 to quantify GHGs emissions depending with the 14 A03strategy and techniques selected. The Table 1 148 scribes some equations reported for the estimation 149 of GHGs emission (Peu et al. 1999; Laguë et al. 2005; 150 Zhang et al. 2005; Sneath et al. 2006; Amon et al. 151 2007; Ngwabie et al. 2009; Wu et al. 2012; Zhu et al. 152 2014).

\subsection{Techniques to measure gas concentration}

\subsubsection{Direct detection by using sensors and analyzers}

Electrochemical, amperometric, or electronic sensors are commonly used for direct detection of gases. However, specific sensors to measure $\mathrm{CH}_{4}$ and $\mathrm{N}_{2} \mathrm{O}$ emission have important limitations. In the case of $\mathrm{CH}_{4}$, its inertness difficult electrochemical reactions due to its high tolerance to oxidation at lower temperatures. It has been found that the strong $\mathrm{C}-\mathrm{H}$ bond requires high temperatures of around $400{ }^{\circ} \mathrm{C}$ for its detection (Kamieniak et al. 2015). For the detection of $\mathrm{N}_{2} \mathrm{O}$, some biosensors using denitrification-enzyme nitrous-oxide reductase have been reported, but the upper value of detection range is around $1 \mathrm{mM}$. This sensitivity is unsuitable to measure $\mathrm{N}_{2} \mathrm{O}$ at atmospheric concentration where a sensitivity in $\mathrm{ppb}$ is necessary (Tsugawa et al. 2012). Thus, the use of sensors for $\mathrm{CH}_{4}$ and $\mathrm{N}_{2} \mathrm{O}$ has been so far limited.

On the other hand, open-path analyzers, such as the LI-7500A and LI-7700 analyzer based on wavelength modulation spectroscopy, have been reported for direct detection of $\mathrm{CH}_{4}$ concentrations with an appropriate resolution at $10 \mathrm{~Hz}$ for continuous measurement in field. (Felber et al. 2015). Also, new fast response analysers based on tunable diode laser (TDL) and quantum cascade laser (QCL) has been developed for $\mathrm{N}_{2} \mathrm{O}$ measurements under field conditions (Rannik et al. 2015). A description on the basic work principle and some specification of gas analyzers is given in Sect. 2.1.4.

\subsubsection{Active and passive sampling}

When direct detection of GHGs is not possible, air samples are collected by using active or passive sampling for subsequent analysis in laboratory or in mobile units to measure gas concentration (Viguria et al. 2015). Different sampling strategies can be applied to collect air samples by using automatic sampling systems, glass tubes, gas sampling bags or diffusive devices. As the quantity of material collected with gas sampling devices is often small, sensitive analytical methods are required to detect and measure concentration of the gas in a short time after collection. A limitation of the sampling is that the gases can react with dust particles, moisture and other compounds. In some case, the gas containers can alter the chemical composition of the target gas and result in an erroneous estimate of the concentration (Lodge $\mathrm{Jr}$ 1988). Active sampling generally requires pumps to pull air towards a collecting device for direct or indirect measuring. Active sampling has being used to estimate $\mathrm{CH}_{4}$ and $\mathrm{N}_{2} \mathrm{O}$ in different studies (Laguë et al. 2005; Zhang et al. 2005; Sneath et al. 2006; Amon et al. 2007). Some considerations, when active sampling is used should be taken into account. For example, when automatic sampling units are used, the tubes used to transport the sampler need to avoid water condensation. The sampling frequency is defined depending upon the variability of the gas target and the required accuracy. It is considered that long measurement time is required to reach a correct estimation of gas emission, because there are significant variations in gas concentrations and air exchange rates. Zhu et al. (2014), have proposed a methodology for a minimum continuous sampling period of 3 days, taking air samples during each hour to capture the diurnal variations of $\mathrm{CH}_{4}$ and $\mathrm{N}_{2} \mathrm{O}$ emission. Barton et al. (2015), reported a wide range analysis of the uncertainties produced in $\mathrm{N}_{2} \mathrm{O}$ emission estimation when the sampling frequency is not correctly defined. On the other hand, passive sampler or passive flux samplers are considered an appropriate tool for longer sampling periods. In the case of $\mathrm{NH}_{3}$ emission, these samplers has been widely used in agricultural sources (Mosquera et al. 2003; Dore et al. 2004). However, these devices have not been reported to sample $\mathrm{CH}_{4}$ and $\mathrm{N}_{2} \mathrm{O}$ emissions to date. Thus, although direct detection using portable gas analyzer is an innovative alternative to measure gas emission, it is important to evaluate and report the costs for your application, the lifetime of the analyzers and the feasibility to measure $\mathrm{CH}_{4}$ and $\mathrm{N}_{2} \mathrm{O}$ emissions at different points. Likewise, sampling strategies need to be appropriately defined

\begin{tabular}{|l|lll|}
\hline & Journal : Medium 11157 & Dispatch : 18-3-2016 & Pages : 13 \\
Article No. : 9394 & $\square$ LE & $\square$ TYPESET \\
MS Code : RESB-D-15-00100 & $\checkmark$ CP & $\checkmark$ DISK \\
\hline
\end{tabular}


Table 1 Equations proposed to quantify GHGs emissions using different techniques of measuring

Dynamic chambers (Aneja et al. 2006)

Static chambers

(Misselbrook et al.

2005)

Tracer gas (Zhang et al. 2005)

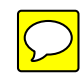

Micrometeorological (Khan et al. 1997)

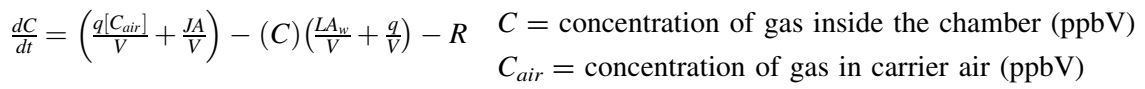

$q=$ flow rate of compressed air through the chamber $(\mathrm{L} / \mathrm{min})$

$V=$ volume of the chamber (L)

$A=$ emission surface area covered by chamber $\left(\mathrm{m}^{2}\right)$

$A_{w}=$ inner surface area of the chamber of inner and upper wall surfaces $\left(\mathrm{m}^{2}\right)$

$t=$ time (s)

$L=$ total loss of gas in the chamber per unit area $\left(\mathrm{m} \mathrm{min}^{-1}\right)$ due to reaction with inner and upper walls of the chamber

$R=$ gas phase reactions inside the chamber

$J=$ emission flux per unit area $\left(\mu \mathrm{g}\right.$ [gas] $\left.\mathrm{m}^{-2} \mathrm{~s}^{-1}\right)$

$$
F=\left(C_{o}-C_{i}\right) \frac{v}{t}
$$

$C_{o}-C_{i}=$ concentration outlet and inlet air $\left(\mu \mathrm{g} \mathrm{m}^{-3}\right)$

$v=$ the volume or air drawn through the tunnel in the sampling period $\left(\mathrm{m}^{3} / \mathrm{s}\right)$

$t=$ time $(\mathrm{s})$

$V=$ effective volume of the enclosure $\left(\mathrm{m}^{3}\right)$

$Q=$ air volume flow rate through the enclosure $\left(\mathrm{m}^{3} / \mathrm{s}\right)$

$C=$ internal concentration of tracer gas at time $(t)$

$C_{e}=$ concentration of tracer gas in the atmosphere

$F=$ tracer injection flow rate $(\mathrm{m} / \mathrm{s})$

$t=$ time (s)

$x=$ distance the wind travels across the pond $(\mathrm{m})$

$u_{z}=$ mean wind speed $\left(\mathrm{ms}^{-1}\right)$ at height $z(\mathrm{~m})$

$\left(C_{l z}-C_{w z}\right)=$ windward (background) and leeward gas concentrations

$z_{o}=$ roughness length (the height at which $u_{z o}=0$ )

$z_{p}=$ height at which the gas concentration, assumed not be affected by the pond $(z p=3.6 \mathrm{~m})$

$z=$ height $(\mathrm{m})$

$E_{G H G}=\mathrm{CO}_{2}, \mathrm{CH}_{4}$ or $\mathrm{N}_{2} \mathrm{O}$ emissions $\left(\mathrm{g} \mathrm{yr}^{-1}\right.$ animal $\left.^{-1}\right)$

$C_{\text {out }}=$ exhaust gas concentration from the animal space (ppmv)

$C_{i n}=$ income gas concentration from the animal space (ppmv)

$Q=$ Average room air exchange rate $\left(\mathrm{m}^{3}\right.$ air $\left.\mathrm{min}^{-1}\right)$

$\mathrm{Na}=$ Number of animals in the room

$P_{a t m}-P_{v}=$ atmospheric pressure at sea level and the vapor pressure $(\mathrm{Pa})$

$T=$ temperature $(\mathrm{K})$

$M_{G H G}=$ characterize the molar masses of $\mathrm{CO}_{2}\left(44 \mathrm{~g} \mathrm{~mol}^{-1}\right)$, $\mathrm{CH}_{4}\left(16 \mathrm{~g} \mathrm{~mol}^{-1}\right)$, or $\mathrm{N}_{2} \mathrm{O}\left(44 \mathrm{~g} \mathrm{~mol}^{-1}\right)$

$M_{\text {air }}=$ molar mass of air $\left(29 \mathrm{~g} \mathrm{~mol}^{-1}\right)$

$287=$ is the thermodynamic constant of air $\left(\mathrm{J} \mathrm{kg}^{-1} \mathrm{~K}^{-1}\right)$

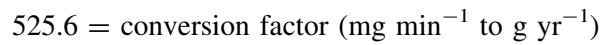


235 and compared with direct detection or measurement to

236 estimate the uncertainty, representation and 237 feasibility.

\subsubsection{Gas chromatography}

239 As mentioned previously, the measurement of GHGs 240 emission requires instruments to measure gas concen241 tration. Gas chromatography with selective detectors, 242 Fourier transform infrared spectroscopy (FTIR) and 243 photoacoustic spectroscopy (PAS) are the techniques 244 usually reported. Gas chromatography with flame 245 ionization detector (FID) is the most common tech246 nique used to measure $\mathrm{CH}_{4}$ concentrations at a 247 detection level of $0.01 \mathrm{ppmv}$ for most of the time 248 depending on the equipment used (Zhou et al. 2003; 249 Zhu et al. 2014). In the case of $\mathrm{N}_{2} \mathrm{O}$ quantification, an 250 electron capture detector (ECD) is commonly used at a 251 detection level of 0.030 ppmv (Rapson and Dacres 25 A0 14). Gas chromatography requires carrier gases, 253 h as zero grade nitrogen. In some case, impurities 254 from these gases interfere with the detection of ECD 255 (Rapson and Dacres 2014).

256 To measure GHGs concentrations directly in the 257 field using GC, a mobile laboratory with temperature 258 control is necessary. The mobile laboratory is 259 equipped with GC analyzer, air pumps, and thermo260 couples to monitor the temperature in ducts, inside and 261 outside the laboratory. Gas chromatographic analysis 262 requires commonly $5 \mathrm{~min}$ and a turnover of less than 2637 min between analyses. A data logger controlled by 264 the computer of the GC is used to acquire and archive 265 various parameters measured during periods of anal266 ysis (Godbout et al. 2012; Rapson and Dacres 2014). 267 Although, gas chromatography permits the measure268 ment of GHGs concentration in the field, the require269 ments limit its application to a small number of 270 sampling sites. However, when samples are collected 271 in field to analyze after in the laboratory; gas 272 chromatography permits the measurement of gas 273 samples from different sampling points. The analysis 274 of gas concentration in laboratory using gas chro275 matography is considered as an alternative strategy, 276 but not reports comparing the accuracy of sampling in 277 field and in the laboratory were identified during this 278 review.

\subsubsection{Spectroscopic techniques}

Spectroscopy is another technique used to measure gas concentration; the concentration is determined by the absorption of radiation when it is transmitted through the air sampler. Infrared, photoacoustic and laser spectroscopy have been used to measure $\mathrm{CO}_{2}, \mathrm{~N}_{2} \mathrm{O}$, $\mathrm{CH}_{4}, \mathrm{H}_{2} \mathrm{O}$ and $\mathrm{CO}$ concentrations. Infrared spectroscopy (IR) is based on irradiation of a sample with IR radiation source, which causes specific resonant frequencies, depending upon the types of molecular bonds present in the sample (Kamieniak et al. 2015). IR uses closed or open path Fourier transform infrared spectrometer (FTIR) to simultaneously measure the concentration of different gases with a frequency of few seconds or minutes (Järvi et al. 2009; Kroon et al. 2010; Detto et al. 2011; McDermitt et al. 2011; Rapson and Dacres 2014). The spectral region used to measure $\mathrm{N}_{2} \mathrm{O}$ and $\mathrm{CH}_{4}$ is around 2188-2224 and 1500-7425 $\mathrm{cm}^{-1}$, respectively. The detection limit depends on the sensitivity of the instrument used. For example, Grutter (2003) reported a detection limit of 0.024 and 0.003 ppm for $\mathrm{CH}_{4}$ and $\mathrm{N}_{2} \mathrm{O}$, respectively; while Ngwabie et al. (2009) reported 0.4 ppm for $\mathrm{CH}_{4}$ and 0.03 ppm for $\mathrm{N}_{2} \mathrm{O}$. The main drawbacks of FTIR and other spectroscopy techniques, such as laser spectroscopy are higher cost and energy requirements. Also, the overestimation or underestimation of gas concentration caused by the interference of non-target gases is other drawback. This interference is generated by overlap spectra of several gases. For example, $\mathrm{N}_{2} \mathrm{O}$ spectra can present interferences with $\mathrm{CH}_{4}, \mathrm{H}_{2} \mathrm{O}, \mathrm{CO}_{2}$ and $\mathrm{CO}$ and generate relative errors of $0.1-3 \%$ (Grutter 2003). Currently, portable analyzers based on infrared spectroscopy (FTIR) are being used to direct detection on $\mathrm{CH}_{4}$. However, the use of these analyzer types to detect $\mathrm{N}_{2} \mathrm{O}$ in field was no identified.

Laser spectroscopy is another technique to quantify gas concentration. This technique is based on the use of optical parametric oscillator or a quantum cascade laser (QCL) as radiation source. These laser sources emit light in the mid-IR range, where the molecules have higher absorption coefficients. Laser spectroscopy is considered the more selective technique for the identification of components from a gaseous mixture, due to its high radiation, narrow line width and high spectral resolution (Köhring et al. 2015).
280

281

282

283

284

285

286

287

288

289

290

291

292

293

294

295

296

297

298

299

300

301

302

303

304

305

306

307

308

309

310

311

312

313

314

315

316

317

318

319

320

321

322

323

324

\begin{tabular}{|l|llll|}
\hline & Journal : Medium 11157 & Dispatch : 18-3-2016 & Pages : 13 \\
Article No. : 9394 & $\square$ LE & $\square$ TYPESET \\
& MS Code : RESB-D-15-00100 & $\checkmark \mathrm{CP}$ & \\
\hline
\end{tabular}


However, the application of this technique to measure GHGs emissions in field is even limited. Recently, the combination of laser and infrared spectroscopy was reported by Tao et al. (2015). They developed an openpath, multiple trace gas mobile by integrating individual open-path analyzers to detect $\mathrm{CO}_{2}, \mathrm{CH}_{4}, \mathrm{~N}_{2} \mathrm{O}$, $\mathrm{H}_{2} \mathrm{O}, \mathrm{NH}_{3}$ and $\mathrm{CO}$ simultaneously at $10 \mathrm{~Hz}$. This analyzer provides a lightweight, compact and lowpower alternative to the closed-path sensors. However, they concluded that more experiments are needed to verify the precision and calibration of this new analyzer while driving, because the power consumption is from a mobile platform. Also, the optimization of the sampling strategy for mobile-based measurements is necessary in order to quantify emissions accurately.

Photoacoustic spectroscopy (PAS) is another technique used to quantify gas concentration. It is based on the generation and detection of radiation and the resonant absorption (Rocha et al. 2012). In this technique, a quantum-cascade laser is used as light source. The difference between PAS and laser spectroscopy is that the samples are exposed to a modulated radiation and the acoustic waves resulting from the absorption of laser radiation produce a sound (photoacoustic effect) which is detected by highly sensitive coupled microphones. These microphones convert the sound signal into an electric signal, which is filtered and detected by an amplifier. Photoacoustic spectroscopy has been used to quantify the concentration of several gases in a range of ppbv and subppbv. In the case of $\mathrm{CH}_{4}$ and $\mathrm{N}_{2} \mathrm{O}$, the detection limit is around 30 and 7 ppb, respectively (Kang et al. 2014; Rapson and Dacres 2014; Köhring et al. 2015). It can be a limiting factor when higher sensitivity is required. The main advantage of PAS detection is that can be portable and to work at atmospheric pressure. PAS is considered a cost efficiency technique with mobility possibility for a continuous measurement (Kang et al. 2014). However in some case, PAS can overestimate $\mathrm{N}_{2} \mathrm{O}$ fluxes by $13.6 \%$ in relation to $\mathrm{GC}$ due to humidity interference in $\mathrm{CO}_{2}, \mathrm{CH}_{4}$ and $\mathrm{N}_{2} \mathrm{O}$ measurements (Nicoloso et al. 2013).

Thus, there is a wide range of techniques to quantify gas concentration, Kamieniak et al. (2015) and Rapson and Dacres (2014) have reported a more detailed description of analytical techniques to quantify $\mathrm{CH}_{4}$ and $\mathrm{N}_{2} \mathrm{O}$ emissions. However, to evaluate the application of these techniques in real conditions, it is necessary to have an exhaustive analysis to compare the technical and economic requirements for a continuous in situ measurement of GHGs emissions. Also, the instrumental stability, random errors of fluxes originate from the stochastic nature of turbulence and correcting procedures that can systematically affect the accuracy of measured fluxes when conducting long term measurements has been suggested.

\subsection{Techniques for measurement of air exchange} rate and air flux

Air exchange rate or ventilation rate represents the volume of air replaced in a specific space per unit of time. It can be expressed as air exchange per minute (ACM) or per hour (ACH). In animal houses, the air exchange is necessary to maintain the health and productivity of farm workers and animals. Hence, the main objective of air exchange is to replace the stale air with fresh air to maintain the indoor air quality within the comfort zone of the animals. For example, the ventilation rate recommended for cattle is around $100 \mathrm{~m}^{3} / \mathrm{h}$ per cow; while for pigs, it is around $60 \mathrm{~m}^{3} / \mathrm{h}$ per pig. However, ventilation rate required for each animal production system is dependent on seasonal and environmental changes (Chastain 2000). The ventilation rate must be estimated according to emission rate of pathogen organisms, dust, $\mathrm{CO}_{2}$ and other gases, such as $\mathrm{NH}_{3}, \mathrm{CH}_{4}$, and $\mathrm{N}_{2} \mathrm{O}$ according to animal heat production. A perfect mixing depends on the ventilation system used to enable homogeneity of air inside the building and also the animal distribution inside the house. The ventilation conditions depend on many parameters, such as seasonal environmental variations, wind speed and direction, temperature, animal heat production, building characteristics, which vary in space and time.

Some techniques to measure ventilation rates include: anemometers, tracer techniques; diffusion of animal-produced $\mathrm{CO}_{2}$ or heat. These techniques have been widely described by different researchers (Van Buggenhout et al. 2009). Tracer techniques and vane and thermal anemometers have been mostly considered appropriate for the measurement of ventilation rate in small buildings with mechanical ventilation and single ventilation outlet. The accuracy of these techniques in these systems has been reported to be

\begin{tabular}{|l|lll|}
\hline Aournal : Medium 11157 & Dispatch : 18-3-2016 & Pages : 13 \\
& Article No. : 9394 & $\square$ LE & $\square$ TYPESET \\
& MS Code : RESB-D-15-00100 & $\checkmark$ CP & $\checkmark$ DISK \\
\hline
\end{tabular}


between 90 and $96 \%$ (McWilliams 2002). However, in large ventilated systems, it is difficult that the tracer follows the same path that the gas of interest due to incomplete mixing by differences among fans or ventilation effectiveness (Scholtens et al. 2004; Khan et al. 2008; Samer et al. 2014). This problem is more evident in naturally ventilated buildings, because in these systems, it is difficult to release the tracer gas with the same dispersion properties as the target gas over a large and open distance. Thus, when a perfect mixing of air is not achieved, the results will not be reliable (Van Buggenhout et al. 2009).

Van Buggenhout et al. (2009) reported a comparison of techniques for measurement of ventilation rate in naturally ventilated systems and they showed lack of accuracy in all the techniques reviewed. The accuracy reported was around 10-15\% using tracer gases and $25 \%$ for hot wire anemometers. These results showed that the measurement of ventilation rate in large buildings with natural ventilation has significant influence on the measurement of GHGs emissions. Since high amounts of GHGs are emitted from mixed systems of animal production which include open areas, it is necessary to develop and evaluate new techniques to improve the estimation of ventilation rate.

Ultrasonic anemometers are generally used to measure air flux with higher frequency. These devices measure wind velocity and temperature in three coordinates. Anemometers are mounted on a horizontal support on a tower. The air flux is estimated by using dispersion models to describe the vertical profiles. The main limitation of air flux measurements is that the fluxes vary spatially, and differ from day-today and within the day in response to multiple factors that regulate production, consumption and emission the GHGs (Zhu et al. 2014).

\section{Techniques for measurement of GHGs emissions in the field}

Gas flux chamber, micrometeorological and tracer gases at animal scale are the techniques more studied for measurement of GHGs emissions from livestock sources. Although these techniques have been widely described in diverse reviews (Storm et al. 2012; Hensen et al. 2013; Fonollosa et al. 2014), the main objective of the present review is to compare results from the evaluation of these techniques in the field describing briefly each one.

\subsection{Gas flux chamber}

This technique consists of obtaining a representative sample from emitting source enclosed in a static or dynamic chamber in order to perform mass balances. In dynamic chambers, controlled air is blown through the chamber and air samples are collected at the inlet and outlet. These chambers are generally used to measure GHGs emissions from liquid surfaces and $\mathrm{CH}_{4}$ from individual or small groups of ruminants to compare gas emissions from feeding diets and to evaluate the use of additives for mitigation of $\mathrm{CH}_{4}$ production in the rumen (Laguë et al. 2005; Sneath et al. 2006; Storm et al. 2012). When dynamic chambers are used to measure $\mathrm{CH}_{4}$ emissions from a sample of animals, an accuracy of around $95 \%$ can be achieved. However, when these results are extrapolated to estimate $\mathrm{CH}_{4}$ emissions from a herd, important uncertainty can be obtained. The overestimation has been associated with the variability of air distribution in the chamber during the test; difference among animals evaluated and the animals comprising the herd due to genetic characteristics and growth stage; differences among types of pasture or crops used to feed to the animals during the measuring and the consumed during the grazing. Currently, new chamber systems have been developed to improve the air exchange rate in the chamber by integration of a series of ventilated hood chambers; a fresh air supply and a system to deliver the air in a metered ventilation (Maia et al. 2015). However, the cost of the measuring system and the data extrapolation was not discussed. In other studies, models, such as Nordic dairy cow model Karoline was used to predict $\mathrm{CH}_{4}$ emissions. This model describes the digestion and metabolism of nutrients. The model integrate the typical range of diets fed to dairy cattle (Ramin and Huhtanen 2015). The model evaluation using observed data from studies reporting $\mathrm{CH}_{4}$ emissions from respiration chamber showed a good relationship between predicted and observed $\mathrm{CH}_{4}$ emissions with a small root mean square error of prediction $\left(\mathrm{R}^{2}=0.93\right)$. Thus, these new developments from the use of active chambers and modelling can be an alternative to estimate $\mathrm{CH}_{4}$ emissions with more accuracy. However, an analysis on the cost to adapt these systems at

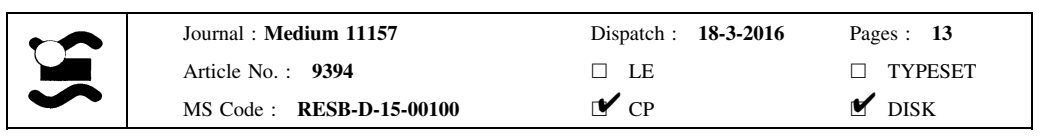


different sampling points will be necessary. Also, it is important to consider that the estimation of GHGs should integrate the seasonal and time variations.

On the other hand, static chambers are generally used to measure $\mathrm{N}_{2} \mathrm{O}$ from agricultural soil surfaces after manure application. In these chambers, no air is blown through the chamber and the variation of concentration is measured over time (Rochette and Eriksen-Hamel 2008). Static chambers are considered relatively inexpensive, versatile for field application and easy to deploy. However, uncertainties of $\mathrm{N}_{2} \mathrm{O}$ emissions around 17-20\% have been reported and associated with the respiratory activity of plants or microorganisms that absorb or release gases during the measurement of emissions. Also, the insertion and removal of chambers during the sampling can cause disruption and gas flux alteration (Rochette and Eriksen-Hamel 2008; Parkin et al. 2012). An inadequate mixing of the headspace air, pressure changes, and increase in headspace gas concentration can affected the estimation of GHGs emission when static chambers are used (Zhu et al. 2014). Some modifications in chamber characteristics and operation were proposed by Parkin et al. (2012). They reported that the flux detection limit of the chamber systems depends on several factors, such as the type of the chamber and respective sampling method, the precision of the instrument, chamber dimensions and operation time. They proposed a model to scale up their results, but their study only considered sampling and analytical precision associated with trace gas concentration measurement. However, it is necessary to evaluate other sources of variability, such as chamber leakage and changes in biological activity during the chamber deployment period.

\subsection{Tracers gases technique to measure $\mathrm{CH}_{4}$ emissions from animal scale}

Other application of tracer gases is related to the estimation of $\mathrm{CH}_{4}$ emissions from enteric fermentation of ruminant animals by using $\mathrm{SF}_{6}$ as tracer gas. In this technique, $\mathrm{SF}_{6}$ is continuously released from a permeation tube inserted in the rumen of the animal. The gas ratio of $\mathrm{SF}_{6}: \mathrm{CH}_{4}$ is determined over a $24 \mathrm{~h}$ period by analysis of the exhaled gases and collected on a PVC canister which is placed around the nose and mouth. The rate at which the gas is released from the permeation tubes is measured a priori in the laboratory
(Storm et al. 2012). Some limitations associated with the estimation of $\mathrm{CH}_{4}$ using tracer techniques are: interferences of canister with grazing, overestimation of feed dry matter intake (DMI), labour intensive due to animal handling, sampling tube obstructions, broken collection tubes and unsuitability of capillary tubes to continuously collect gas at a constant rate for $24 \mathrm{~h}$ (Hammond et al. 2015).

A system to measure $\mathrm{CH}_{4}$ emissions by using propane as gas tracer technique combined with a dynamic chamber including systems for animal radiofrequency identification, baiting and a measurement was reported by Hristov et al. (2015). This technique is known as automated head-chamber system (AHCS). It is based on periodic attraction of animals to a AHCS unit placed in a grazing system. When the animals are attracted to AHCS, a fan pulls air over its head to collect $\mathrm{CH}_{4}$ and $\mathrm{CO}_{2}$ into an air intake manifold. The air flow velocity is measured with a hot-film anemometer. A continuous subsample of air is then extracted and routed into a secondary sample filter to analyze gas concentration using two non-dispersive infrared analyzers. AHCS also includes additional sensors to measure air temperature, and humidity; bait drop, atmospheric pressure, flow rate of the gas tracer, and head position. The main advantage of AHCS over respiration chambers is that the natural environment of animals is not restricted. The authors considered that this system is less expensive than a traditional respiration chamber and much simpler to operate compared with $\mathrm{SF}_{6}$ tracer method. However, the data registered to estimate $\mathrm{CH}_{4}$ emissions is dependent on the number of animals attracted to AHCS and hence it could not be representative.

\subsection{Micrometeorological techniques}

Different micrometeorological techniques have been reported for the measurement of GHGs emissions from housing or feedlot facilities, manure storage and manure applications on soil (Harper et al. 2011; McGinn 2013). These techniques are based on the use of meteorological sensors and gas analyzers of higher frequency to follow simultaneous and contiguous fluctuations of emissions (Storm et al. 2012; Vergé et al. 2012; Hensen et al. 2013). Emissions are calculated by measuring the horizontal or vertical concentration and meteorological data, such as wind speed, wet and dry-bulb air temperatures, net

\begin{tabular}{|l|lll|}
\hline Journal : Medium 11157 & Dispatch : 18-3-2016 & Pages : 13 \\
& Article No. : 9394 & $\square$ LE & $\square$ TYPESET \\
MS Code : RESB-D-15-00100 & $\checkmark$ CP & $\checkmark$ DISK \\
\hline
\end{tabular}


radiation, and heat fluxes. To measure gas concentration, these techniques use laser and infrared spectroscopy analyzers or gas sampling techniques (Hensen et al. 2013; Fonollosa et al. 2014; Laville et al. 2015; Viguria et al. 2015).

Micrometeorological techniques include flux gradient (Köhring et al. 2015), eddy covariance (EC), relaxed eddy accumulation (REA), integrated horizontal flux (IHF), boundary-layer budgeting (BLB), vertical radial plume mapping (VRPM) and inverse dispersion analysis using models, such as backward Lagrangian stochastic (bLS) model (Harper et al. 2011; Fonollosa et al. 2014; Rapson and Dacres 2014; Laville et al. 2015). The differences among micrometeorological techniques are related with the type of analyzer used to determine concentrations, sampling location, and geometric configuration of the emission source, wind conditions and the process used to calculate the emission flux. For example, VRPM technique uses an open path optical analyzer to estimate the horizontal flux of gas emissions passing from the downwind emission source, whilst bLS technique calculates the emissions from distributed sources with a backward Lagrangian Stochastic dispersion model measuring the gas concentration in downwind or even over the source using only a single analyzer (Khan et al. 1997; Anderson et al. 2004; Kroon et al. 2007; Mammarella et al. 2010; Ro et al. 2011; McGinn 2013; Fonollosa et al. 2014; Rapson and Dacres 2014). Although these techniques have been suggested for grazing and mixed production systems, the emission values can result in an overestimation of up to 10-27\% in comparison with the gas tracer technique using $\mathrm{SF}_{6}$ (Grainger et al. 2007). The principal limitation of micrometeorological techniques is that they are dependent on simplifying assumptions regarding uniformity and homogeneity of airflow which is difficult to reach under real conditions. Also, the required equipment is often costly (Bonifacio et al. 2015).

Table 2 shows results of $\mathrm{CH}_{4}$ and $\mathrm{N}_{2} \mathrm{O}$ emissions from different sources, using the techniques described earlier. It can be seen that for open sources such as feedlot, grazing cattle or buildings with mechanical ventilation, micrometeorological techniques have been used. In the case of slurry storage, a dynamic chamber is the common technique used to quantify GHGs emissions (Husted 1993; Peu et al. 1999; Laguë et al. 2005; Sneath et al. 2006; Amon et al. 2007).
Also, it can see that the values of $\mathrm{CH}_{4}$ and $\mathrm{N}_{2} \mathrm{O}$ emissions dependent on many factors such as environmental conditions, type of production system, type of emission source, physical and chemical characteristics of the emission source, manure management processes, ventilation type if it is in the animal house, measuring method selected and the combination of techniques used to measure gas concentration and air flux; the strategies applied to analyse the sample, type and time of sampling, characteristic of the farm, year season. Thus, the estimation of GHGs from livestock sector faces challenges to cover in next years.

\section{Challenges and perspective to measure nitrous oxide and methane emissions from livestock sector}

- The trends on consumption and production of livestock products allow visualizing the problematic to face the target to decrease GHGs emissions. Livestock sector integrates a wide variety of production models around the world with specific characteristics that require particular strategies to measure GHGs emissions. Since these production models are dependent on cultural, socio-economic and environmental conditions, substantial seasonal and spatial variability in GHGs emissions among sites have been identified. Thus, to achieve an accurate assessment and monitoring of gas emissions represents a big challenge; because livestock sector requires continuous measurement and a higher number of sampling sites which implies higher cost.

- Unlike in other sectors involving GHGs emissions, in livestock sector, the strategy to establish mechanism of control and measuring of GHGs emissions is not clear. This situation makes it difficult to define an appropriate cost and complexity in the strategies and methods required for a correct estimation of $\mathrm{CH}_{4}$ and $\mathrm{N}_{2} \mathrm{O}$ in livestock sources. As the grade of complexity and cost of a method of measurement is relative to who adopts the approach. Thus, it is necessary to define criteria to establish user type, cost, technology degree and complexity of the methods required to measure GHGs emission in real conditions.

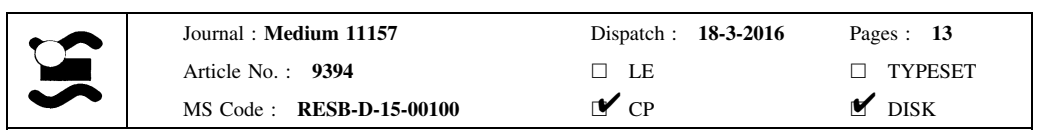


Table 2 Nitrous oxide and methane emissions from livestock sources using different measurement techniques

\begin{tabular}{|c|c|c|c|c|c|}
\hline Emission source & $\begin{array}{l}\mathrm{CH}_{4} \\
\text { emission }\end{array}$ & $\begin{array}{l}\mathrm{N}_{2} \mathrm{O} \\
\text { emission }\end{array}$ & $\begin{array}{l}\text { Technique used to } \\
\text { quantify emission }\end{array}$ & $\begin{array}{l}\text { Technique used to measure } \\
\text { concentration/and flux }\end{array}$ & References \\
\hline $\begin{array}{l}\text { Feedlot with dairy } \\
\text { cattle }\end{array}$ & $\begin{array}{l}16.88 \mathrm{~g} / \mathrm{kg} \\
\text { of milk } \\
397 \mathrm{~g} / \mathrm{cow} \\
\text { day } \\
279 \mathrm{~g} / \mathrm{heifer} \\
\text { day }\end{array}$ & $\begin{array}{l}1.68 \mathrm{~g} \mathrm{~N}_{2} \mathrm{O} / \\
\mathrm{kg} \text { of milk } \\
35.7 \mathrm{~g} / \mathrm{cow} \\
\text { day } \\
24.2 \mathrm{~g} / \\
\text { heifer day }\end{array}$ & Micrometeorological & $\begin{array}{l}\text { Active sampling and laboratory analysis/ } \\
\text { Anemometer and backward } \\
\text { Lagrangian stochastic inverse- } \\
\text { dispersion technique }\end{array}$ & $\begin{array}{l}\text { (Zhu et al. } \\
\text { 2014) }\end{array}$ \\
\hline $\begin{array}{l}\text { Naturally ventilated } \\
\text { dairy cattle } \\
\text { building }\end{array}$ & $\begin{array}{l}200-400 \mathrm{~g} / \\
\text { HPU* day }^{*}\end{array}$ & $\begin{array}{l}<4 \mathrm{~g} / \mathrm{HPU} \\
\text { day }\end{array}$ & $\begin{array}{l}\text { Tracer gas- } \\
\text { multipoint } \\
\text { sampling }\end{array}$ & $\begin{array}{l}\text { Multiplexer gas monitor in situ-GC/SF} 6 \\
\text { as gas tracer }\end{array}$ & $\begin{array}{l}\text { (Zhang } \\
\text { et al. } \\
\text { 2005) }\end{array}$ \\
\hline $\begin{array}{l}\text { Naturally ventilated } \\
\text { dairy cattle } \\
\text { building }\end{array}$ & $\begin{array}{l}290-230 \mathrm{~g} / \\
\text { HPU day }\end{array}$ & $\begin{array}{l}\text { Low } \\
\text { emissions } \\
\text { into the } \\
\text { building }\end{array}$ & $\begin{array}{l}\text { Tracer gas- } \\
\text { multipoint } \\
\text { sampling }\end{array}$ & $\begin{array}{l}\text { Photoacoustic spectroscopy/ultrasonic } \\
\text { anemometers }\end{array}$ & $\begin{array}{l}\text { (Wu et al. } \\
\text { 2012) }\end{array}$ \\
\hline $\begin{array}{l}\text { Naturally ventilated } \\
\text { dairy cattle } \\
\text { building }\end{array}$ & $\begin{array}{l}8-11.2 \mathrm{~g} / \\
\text { HPU day }\end{array}$ & $\begin{array}{l}\text { Low } \\
\text { emissions } \\
\text { into the } \\
\text { building }\end{array}$ & $\begin{array}{l}\text { Tracer gas- } \\
\text { multipoint } \\
\text { sampling }\end{array}$ & $\begin{array}{l}\text { Photoacoustic multi-gas analyzer/ } \\
\text { ultrasonic anemometers }\end{array}$ & $\begin{array}{l}\text { (Ngwabie } \\
\text { et al. } \\
\text { 2009) }\end{array}$ \\
\hline $\begin{array}{l}\text { Ventilated housing } \\
\text { for fattening pigs } \\
\text { (with manure } \\
\text { removal) }\end{array}$ & $\begin{array}{l}1.48 \mathrm{~g} / \mathrm{pig} \\
\text { place day }\end{array}$ & $\begin{array}{r}0.070 \mathrm{~g} / \mathrm{pig} \\
\text { place day }\end{array}$ & Micrometeorological & $\begin{array}{l}\text { FTIR spectroscopy-analysis in situ/ } \\
\text { ultrasonic anemometers }\end{array}$ & $\begin{array}{l}\text { (Amon } \\
\text { et al. } \\
\text { 2007) }\end{array}$ \\
\hline $\begin{array}{l}\text { Ventilated housing } \\
\text { for fattening pigs } \\
\text { (without manure } \\
\text { removal) }\end{array}$ & $\begin{array}{l}3.4 \mathrm{~g} / \mathrm{pig} \\
\text { place day }\end{array}$ & $\begin{array}{l}0.11 \mathrm{~g} / \mathrm{pig} \\
\text { place day }\end{array}$ & Micrometeorological & $\begin{array}{l}\text { FTIR spectroscopy-analysis in situ/ } \\
\text { ultrasonic anemometers }\end{array}$ & $\begin{array}{l}\text { (Amon } \\
\text { et al. } \\
2007)\end{array}$ \\
\hline $\begin{array}{l}\text { Liquid animal } \\
\text { slurries }\end{array}$ & Not reported & $\begin{array}{l}1.90-5.98 \mathrm{~g} / \\
\mathrm{m}^{2} \text { day }\end{array}$ & Dynamic chamber & $\begin{array}{l}\text { Active sampling-GC and infrared } \\
\text { spectrophotometer/flow meter }\end{array}$ & $\begin{array}{l}\text { (Peu et al. } \\
1999)\end{array}$ \\
\hline Liquid pig manure & $\begin{array}{l}3.75 \mathrm{~g} \mathrm{CO}_{2} \\
\text { equivalent/ } \\
\mathrm{kg} \text { day }\end{array}$ & $\begin{array}{l}<0.01 \mathrm{~g} \\
\mathrm{CO}_{2} \\
\text { equivalent/ } \\
\mathrm{kg} \text { day }\end{array}$ & Dynamic chamber & Active sampling in field GC/flow meter & $\begin{array}{l}\text { (Laguë } \\
\text { et al. } \\
2005)\end{array}$ \\
\hline $\begin{array}{l}\text { Pig slurries (warm- } \\
50 \text { days) }\end{array}$ & $5 \mathrm{~g} / \mathrm{m}^{3}$ day & $\begin{array}{l}0.46 \mathrm{~g} / \mathrm{m}^{3} \\
\text { day }\end{array}$ & Dynamic chamber & $\begin{array}{l}\text { FTIR spectroscopy-analysis in situ/flow } \\
\text { meter }\end{array}$ & $\begin{array}{l}\text { (Amon } \\
\text { et al. } \\
2007)\end{array}$ \\
\hline $\begin{array}{l}\text { Pig slurries (cold- } \\
50 \text { days) }\end{array}$ & $\begin{array}{l}3.2 \mathrm{~g} / \mathrm{m}^{3} \\
\text { day }\end{array}$ & $\begin{array}{l}0.72 \mathrm{~g} / \mathrm{m}^{3} \\
\text { day }\end{array}$ & Dynamic chamber & $\begin{array}{l}\text { FTIR spectroscopy-analysis in situ/flow } \\
\text { meter }\end{array}$ & $\begin{array}{l}\text { (Amon } \\
\text { et al. } \\
\text { 2007) }\end{array}$ \\
\hline Slurry storage & $\begin{array}{l}35-26 \mathrm{~g} \mathrm{Cl} \\
\mathrm{m}^{3} \text { day }\end{array}$ & $\approx 0$ & $\begin{array}{l}\text { Tracer gas- } \\
\text { multipoint } \\
\text { sampling }\end{array}$ & $\begin{array}{l}\text { Multiplexer gas monitor-GC/SF } 6 \text { as gas } \\
\text { tracer }\end{array}$ & $\begin{array}{l}\text { (Sneath } \\
\text { et al. } \\
\text { 2006) }\end{array}$ \\
\hline $\begin{array}{l}\text { Pig solid manure } \\
\text { (sumer-31 days) }\end{array}$ & $\begin{array}{c}17.9-92 \mathrm{~g} / \\
\mathrm{m}^{3} \mathrm{dav}^{3}\end{array}$ & Not reported & Dynamic chamber & $\begin{array}{l}\text { Active sampling and laboratory analysis/ } \\
\text { Anemometer and backward } \\
\text { Lagrangian stochastic inverse- } \\
\text { dispersion technique }\end{array}$ & $\begin{array}{l}\text { (Zhu et al. } \\
\text { 2014) }\end{array}$ \\
\hline
\end{tabular}

$* \mathrm{HPU}=1000 \mathrm{~W}$ of total heat produced by the livestock at an environmental temperature of $20{ }^{\circ} \mathrm{C}$. Some values were modified for the standardization of the units of measuring and can differ of the values reported in the original source

- Special attention should be given to non-dairy and dairy cattle production, as it contributes about twothirds of total GHGs emissions from livestock sector. Mixed and grazing systems are commonly used for their production. In these systems, it is difficult to measure GHGs emissions as they

\begin{tabular}{|l|lll|}
\hline Journal : Medium 11157 & Dispatch : 18-3-2016 & Pages : 13 \\
& Article No. : 9394 & $\square$ LE & $\square$ TYPESET \\
& MS Code : RESB-D-15-00100 & $\checkmark \mathrm{CP}$ & $\searrow$ DISK \\
\hline
\end{tabular}


include open areas where air flow cannot be measured accurately. In the case of confinement systems, to produce ruminants and non-ruminants, tracer techniques and strategies of sampling to measure gas concentration could be the most appropriate technique to measure GHGs emissions. However, due to the fact that the measurement of GHGs emissions requires equipment to measure gas concentration and air flow rate, the cost and requirements for the continual measurement in the field remains a challenge as the available techniques are considered complex and expensive. Thus, new methods, techniques and instruments are necessary to measure simultaneous and continuously the emissions from livestock sector.

- It is necessary to develop reference methods for the comparison of available and new techniques developed for the measurement of $\mathrm{CH}_{4}$ and $\mathrm{N}_{2} \mathrm{O}$ emissions from different livestock sources, as while considering the multiple alternatives to measure gas concentration, air flux, detection or sampling strategies, there are many combinations to quantify GHGs emissions.

- Passive flux sampling is considered a robust technique with lower level of operational requirements and capital investment to set up a measurement in agricultural sources to measure $\mathrm{NH}_{3}$ emissions from soil, manure management and buildings with mechanical ventilation. However, until date, its application to measure GHGs emissions is not reported. Thus, it could be put in perspective to evaluate the feasibility of this technique to quantify GHGs emissions from some livestock sources.

Acknowledgments Our sincere thanks go to Agriculture and Agri-Food Canada for the economic support by means of the Agricultural Greenhouse Gases Program (AGGP), and INRSETE to the Instituto Tecnológico Superior de Perote (ITSPe) for the support and collaboration in the research stage of main author, and to the Program for the Professional development of Professors (Prodep-Mexico) for the grant that let to perform this research stage.

\section{References}

Amon B, Kryvoruchko V, Fröhlich M, Amon T, Pöllinger A, Mösenbacher I, Hausleitner A (2007) Ammonia and greenhouse gas emissions from a straw flow system for fattening pigs: housing and manure storage. Livest Sci 112(3): 199-207

Anderson MC, Norman J, Mecikalski JR, Torn RD, Kustas WP, Basara JB (2004) A multiscale remote sensing model for disaggregating regional fluxes to micrometeorological scales. J Hydrometeorol 5(2):343-363

Arogo J, Westerman P, Heber A (2003) A review of ammonia emissions from confined swine feeding operations. Trans ASAE 46(3):805-817

Asner GP, Elmore AJ, Olander LP, Martin RE, Harris AT (2004) Grazing systems, ecosystem responses, and global change. Annu Rev Environ Resour 29:261-299

Barton L, Wolf B, Rowlings D, Scheer C, Kiese R, Grace P, Stefanova K, Butterbach-Bahl K (2015) Sampling frequency affects estimates of annual nitrous oxide fluxes. Sci Rep 5

Bonifacio HF, Rotz CA, Leytem AB, Waldrip HM, Todd RW (2015) Process-based modeling of ammonia and nitrous oxide emissions from open-lot beef and dairy facilities. Trans ASABE 58(3):827-846

Chastain JP (2000) Design and management of natural ventilation systems. Proceedings Dairy Housing and Equipment Systems: Managing and Planning for Profitability (NRAES-129), Plant and Life Sciences Publishing, Ithaca, pp 147-163

Crutzen P, Sanhueza E, Brenninkmeijer C (2006) Methane production from mixed tropical savanna and forest vegetation in Venezuela. Atmos Chem Phys Discuss 6: 3093-3097

Detto M, Verfaillie J, Anderson F, Xu L, Baldocchi D (2011) Comparing laser-based open-and closed-path gas analyzers to measure methane fluxes using the eddy covariance method. Agric For Meteorol 151(10):1312-1324

Dore C, Jones B, Scholtens R, Huis J, Burgess L, Phillips V (2004) Measuring ammonia emission rates from livestock buildings and manure stores-Part 2: comparative demonstrations of three methods on the farm. Atmos Environ 38(19):3017-3024

FAO (2014) Agriculture's greenhouse gas emissions on the rise. http://www.fao.org/news/story/en/item/216137/icode/. February 2014

FAOSTAT F (2014) Food and Agricultural Organization of the United Nations. 2014

FAOSTAT (2015) Agricultural statistics database. Rome: Word Agricultural Information Centre. June 2015

Felber R, Münger A, Neftel A, Ammann C (2015) Eddy covariance methane flux measurements over a grazed pasture: effect of cows as moving point sources. Biogeosci Discuss 12(4):3419-3468

Fonollosa J, Rodríguez-Luján I, Trincavelli M, Vergara A, Huerta R (2014) Chemical discrimination in turbulent gas mixtures with mox sensors validated by gas chromatography-mass spectrometry. Sensors 14(10):19336-19353

Gerber PJ, Steinfeld H, Henderson B, Mottet A, Opio C, Dijkman J, Falcucci A, Tempio G (2013) Tackling climate change through livestock: a global assessment of emissions and mitigation opportunities, Food and Agriculture Organization of the United Nations (FAO)

Godbout S, Pelletier F, Palacios J, Feddes J, Larouche J, Belzile M, Fournel S, Lemay S (2012) Greenhouse Gas Emissions Non-Cattle Confinement Buildings: Monitoring, Emission

\begin{tabular}{|l|lll|}
\hline Journal : Medium 11157 & Dispatch : 18-3-2016 & Pages : 13 \\
& Article No. : 9394 & $\square$ LE & $\square$ TYPESET \\
MS Code : RESB-D-15-00100 & $\smile_{\mathrm{CP}}$ & $\checkmark$ DISK \\
\hline
\end{tabular}


Factors and Mitigation. INTECH Open Access Publisher, Rijeka

Grainger C, Clarke T, Mcginn S, Auldist M, Beauchemin K, Hannah M, Waghorn G, Clark H, Eckard R (2007) Methane emissions from dairy cows measured using the sulfur hexafluoride $\left(\mathrm{SF}_{6}\right)$ tracer and chamber techniques. J Dairy Sci 90(6):2755-2766

Grutter M (2003) Multi-Gas analysis of ambient air using FTIR spectroscopy over Mexico City. Atmosfera 16(1):1-14

Hafla AN, Macadam JW, Soder KJ (2013) Sustainability of US organic beef and dairy production systems: soil, plant and cattle interactions. Sustainability 5:3009-3034

Hammond K, Humphries D, Crompton L, Green C, Reynolds C (2015) Methane emissions from cattle: estimates from short-term measurements using a GreenFeed system compared with measurements obtained using respiration chambers or sulphur hexafluoride tracer. Anim Feed Sci Technol 203:41-52

Harper L, Denmead O, Flesch T (2011) Micrometeorological techniques for measurement of enteric greenhouse gas emissions. Anim Feed Sci Technol 166:227-239

Hensen A, Skiba U, Famulari D (2013) Low cost and state of the art methods to measure nitrous oxide emissions. Environ Res Lett 8(2):025022

Herrero M, Thornton PK, Notenbaert AM, Wood S, Msangi S, Freeman H, Bossio D, Dixon J, Peters M, Steeg J (2010) Smart investments in sustainable food production: revisiting mixed crop-livestock systems

Hristov AN, Oh J, Giallongo F, Frederick T, Weeks H, Zimmerman PR, Harper MT, Hristova RA, Zimmerman RS, Branco AF (2015) The use of an automated system (GreenFeed) to monitor enteric methane and carbon dioxide emissions from ruminant animals. J Vis Exp 103:8

Husted S (1993) An open chamber technique for determination of methane emission from stored livestock manure. Atmos Environ Part A: Gen Top 27(11):1635-1642

Järvi L, Mammarella I, Eugster W, Ibrom A, Siivola E, Dellwik E, Keronen P, Burba G, Vesala T (2009) Comparison of net $\mathrm{CO}_{2}$ fluxes measured with open-and closed-path infrared gas analyzers in an urban complex environment. Boreal Environ Res 14:499-514

Kamieniak J, Randviir EP, Banks CE (2015) The latest developments in the analytical sensing of methane. TrAC Trends Anal Chem 73:146-157

Kang S, Kim S, Kang S, Lee J, Cho C-S, Sa J-H, Jeon E-C (2014) A study on $\mathrm{N}_{2} \mathrm{O}$ measurement characteristics using photoacoustic spectroscopy (PAS). Sensors 14(8):14399

Khan RZ, Müller C, Sommer SG (1997) Micrometeorological mass balance technique for measuring $\mathrm{CH}_{4}$ emission from stored cattle slurry. Biol Fertil Soils 24(4):442-444

Khan N, Su Y, Riffat SB (2008) A review on wind driven ventilation techniques. Energy Build 40(8):1586-1604

Köhring M, Böttger S, Willer U, Schade W (2015) LED-absorption-QEPAS sensor for biogas plants. Sensors 15(5): 12092

Kroon P, Hensen A, Jonker H, Zahniser M, Van't Veen W, Vermeulen A (2007) Suitability of quantum cascade laser spectroscopy for $\mathrm{CH}_{4}$ and $\mathrm{N}_{2} \mathrm{O}$ eddy covariance flux measurements. Biogeosciences 4(5):2007

Kroon P, Schrier-Uijl A, Hensen A, Veenendaal E, Jonker H (2010) Annual balances of $\mathrm{CH}_{4}$ and $\mathrm{N}_{2} \mathrm{O}$ from a managed fen meadow using eddy covariance flux measurements. Eur J Soil Sci 61(5):773-784

Laguë C, Gaudet E, Agnew J, Fonstad T (2005) Greenhouse gas emissions from liquid swine manure storage facilities in Saskatchewan. Trans ASAE 48(6):2289-2296

Laville P, Neri S, Continanza D, Vero LF, Bosco S, Virgili G (2015) Cross-validation of a mobile $\mathrm{N}_{2} \mathrm{O}$ flux prototype (IPNOA) using micrometeorological and chamber methods. J Energy Power Eng 9:375-385

Lodge JP Jr (1988) Methods of air sampling and analysis. CRC Press, Boca Raton

Maia GD, Ramirez BC, Green AR, Rodríguez LF, Segers JR, Shike DW, Gates RS (2015) A novel ruminant emission measurement system: Part I. Design evaluation and description. Trans ASABE 58(3):749-762

Mammarella I, Werle P, Pihlatie M, Eugster W, Haapanala S, Kiese R, Markkanen T, Rannik Ü, Vesala T (2010) A case study of eddy covariance flux of $\mathrm{N}_{2} \mathrm{O}$ measured within forest ecosystems: quality control and flux error analysis. Biogeosciences 7(2):427-440

McDermitt D, Burba G, Xu L, Anderson T, Komissarov A, Riensche B, Schedlbauer J, Starr G, Zona D, Oechel W (2011) A new low-power, open-path instrument for measuring methane flux by eddy covariance. Appl Phys B 102(2):391-405

McGinn S (2013) Developments in micrometeorological methods for methane measurements. Animal 7(s2): 386-393

McWilliams J (2002) Review of air flow measurement techniques. Lawrence Berkeley National Laboratory, Berkeley

Monteny G-J, Bannink A, Chadwick D (2006) Greenhouse gas abatement strategies for animal husbandry. Agric Ecosyst Environ 112(2): 163-170

Mosquera LJ, Ogink N, Scholtens R (2003) Using passive flux samplers to determine the ammonia emission from mechanically ventilated animal houses

Murray P, Moss A, Lockyer D, Jarvis S (1999) A comparison of systems for measuring methane emissions from sheep. J Agric Sci 133(04):439-444

Ngwabie N, Jeppsson K-H, Nimmermark S, Swensson C, Gustafsson G (2009) Multi-location measurements of greenhouse gases and emission rates of methane and ammonia from a naturally-ventilated barn for dairy cows. Biosyst Eng 103(1):68-77

Nicoloso RDS, Bayer C, Denega GL, Oliveira PAVD, Higarashi MM, Corrêa JC, Lopes LDS (2013) Gas chromatography and photoacoustic spectroscopy for the assessment of soil greenhouse gases emissions. Ciênc Rural 43(2):262-269

Parkin TB, Venterea RT, Hargreaves SK (2012) Calculating the detection limits of chamber-based soil greenhouse gas flux measurements. J Environ Qual 41(3):705-715

Peu P, Beline F, Martinez J (1999) A floating chamber for estimating nitrous oxide emissions from farm scale treatment units for livestock wastes. J Agric Eng Res 73(1): 101-104

Ramin M, Huhtanen P (2015) Nordic dairy cow model Karoline in predicting methane emissions: 2. Model evaluation. Livest Sci 178:81-93

Rannik Ü, Haapanala S, Shurpali N, Mammarella I, Lind S, Hyvönen N, Peltola O, Zahniser M, Martikainen P, Vesala $\mathrm{T}$ (2015) Intercomparison of fast response commercial gas

\begin{tabular}{|l|lll|}
\hline & Journal : Medium 11157 & Dispatch : 18-3-2016 & Pages : 13 \\
Article No. : 9394 & $\square$ LE & $\square$ TYPESET \\
& MS Code : RESB-D-15-00100 & $\checkmark \mathrm{CP}$ & $\checkmark$ DISK \\
\hline
\end{tabular}


analysers for nitrous oxide flux measurements under field conditions. Biogeosciences 12(2):415-432

Rapson TD, Dacres H (2014) Analytical techniques for measuring nitrous oxide. TrAC Trends Anal Chem 54:65-74

Rearte D, Pordomingo A (2014) The relevance of methane emissions from beef production and the challenges of the Argentinean beef production platform. Meat Sci 98(3): $355-360$

Ro KS, Johnson MH, Hunt PG, Flesch TK (2011) Measuring trace gas emission from multi-distributed sources using vertical radial plume mapping (VRPM) and backward Lagrangian stochastic (bLS) techniques. Atmosphere 2(3):553-566

Rocha MV, Sthel MS, Silva MG, Paiva LB, Pinheiro FW, Miklos A, Vargas H (2012) Quantum-cascade laser photoacoustic detection of methane emitted from natural gas powered engines. Appl Phys B-Lasers Opt 106(3):701-706 Rochette P, Eriksen-Hamel NS (2008) Chamber measurements of soil nitrous oxide flux: are absolute values reliable? Soil Sci Soc Am J 72(2):331-342

Samer M, Muller HJ, Fiedler M, Berg W, Brunsch R (2014) Measurement of ventilation rate in livestock buildings with radioactive tracer gas technique: theory and methodology. Indoor Built Environ 23(5):692-708

Scholtens R, Dore C, Jones B, Lee D, Phillips V (2004) Measuring ammonia emission rates from livestock buildings and manure stores - part 1: development and validation of external tracer ratio, internal tracer ratio and passive flux sampling methods. Atmos Environ 38(19):3003-3015

Sneath R, Beline F, Hilhorst M, Peu P (2006) Monitoring GHG from manure stores on organic and conventional dairy farms. Agric Ecosyst Environ 112(2):122-128

Solomon S (2007) Climate change 2007-the physical science basis: working group I contribution to the fourth assessment report of the IPCC. Cambridge University Press, Cambridge

Storm IMLD, Hellwing ALF, Nielsen NI, Madsen J (2012) Methods for measuring and estimating methane emission from rumiants. Animals 2:160-183

Stubbs M (2010) Renewable Energy Programs in the 2008 Farm Bill
Tao L, Sun K, Miller DJ, Pan D, Golston LM, Zondlo MA (2015) Low-power, open-path mobile sensing platform for high-resolution measurements of greenhouse gases and air pollutants. Appl Phys B-Lasers Opt 119(1):153-164

Tsugawa W, Shimizu H, Tatara M, Ueno Y, Kojima K, Sode K (2012) Nitrous oxide sensing using oxygen-insensitive direct-electron-transfer-type nitrous oxide reductase. Electrochemistry 80(5):371-374

Van Beek CL, Meerburg BG, Schils RL, Verhagen J, Kuikman PJ (2010) Feeding the world's increasing population while limiting climate change impacts: linking $\mathrm{N}_{2} \mathrm{O}$ and $\mathrm{CH}_{4}$ emissions from agriculture to population growth. Environ Sci Policy 13(2):89-96

Van Buggenhout S, Van Brecht A, Özcan SE, Vranken E, Van Malcot W, Berckmans D (2009) Influence of sampling positions on accuracy of tracer gas measurements in ventilated spaces. Biosyst Eng 104(2):216-223

Vergé XPC, Dyer JA, Worth DE, Smith WN (2012) A greenhouse gas and soil carbon model for estimating the carbon footprint of livestock production in Canada. Animals 2:437-454

Viguria M, Sanz-Cobeña A, López DM, Arriaga H, Merino P (2015) Ammonia and greenhouse gases emission from impermeable covered storage and land application of cattle slurry to bare soil. Agric Ecosyst Environ 199:261-271

Wu W, Zhang G, Kai P (2012) Ammonia and methane emissions from two naturally ventilated dairy cattle buildings and the influence of climatic factors on ammonia emissions. Atmos Environ 61:232-243

Zhang G, Strøm JS, Li B, Rom HB, Morsing S, Dahl P, Wang C (2005) Emission of ammonia and other contaminant gases from naturally ventilated dairy cattle buildings. Biosyst Eng 92(3):355-364

Zhou Y, Wang C, Firor R (2003) Analysis of permanent gases and methane with the Agilent 6820 gas chromatograph. Agilent Technologies, Santa Clara

Zhu G, Ma X, Gao Z, Ma W, Li J, Cai Z (2014) Characterizing $\mathrm{CH}_{4}$ and $\mathrm{N}_{2} \mathrm{O}$ emissions from an intensive dairy operation in summer and fall in China. Atmos Environ 83:245-253

\begin{tabular}{|l|lll|}
\hline Journal : Medium 11157 & Dispatch : 18-3-2016 & Pages : 13 \\
Article No. : 9394 & $\square$ LE & $\square$ TYPESET \\
MS Code : RESB-D-15-00100 & $\checkmark \mathrm{CP}$ & $\checkmark$ DISK \\
\hline
\end{tabular}


Journal : 11157

Article : 9394

\section{Author Query Form}

算 Springer

the language of science

\section{Please ensure you fill out your response to the queries raised below and return this form along with your corrections}

Dear Author

During the process of typesetting your article, the following queries have arisen. Please check your typeset proof carefully against the queries listed below and mark the necessary changes either directly on the proof/online grid or in the 'Author's response' area provided below

\begin{tabular}{|l|l|l|}
\hline Query & Details Required & Author's Response \\
\hline AQ1 & $\begin{array}{l}\text { Please check and confirm the affiliations have been correctly identified and amend if } \\
\text { necessary. }\end{array}$ & \\
\hline AQ2 & Please check and confirm the city name for affiliation 4. & \\
\hline AQ3 & $\begin{array}{l}\text { References Aneja et al. (2006), Misselbrook et al (2005) are cited in text but not provided in } \\
\text { the reference list. Please provide references in the list or delete these citations. }\end{array}$ & \\
\hline AQ4 & $\begin{array}{l}\text { We have changed the following author name Rapsen to Rapson in reference list and citation. } \\
\text { please check and confirm. }\end{array}$ & \\
\hline AQ5 & $\begin{array}{l}\text { Please provide the complete details of the references Barton et al (2015), Herrero et al (2010), } \\
\text { Mosquera et al (2003). }\end{array}$ & \\
\hline AQ6 & $\begin{array}{l}\text { Please check and confirm the publisher location of the references Godbout et al (2012), } \\
\text { McWilliams (2002), Zhou et al (2003). }\end{array}$ & \\
\hline
\end{tabular}

